\title{
Clinical evaluation of the function of hypothalamo-pituitary-thyroid axis in children with central nervous system infections
}

\author{
Fuyong Jiao ${ }^{1 *}$, Xiaoyan Zhang ${ }^{1}$, Taomin Bai ${ }^{1}$, Jing Lin ${ }^{1}$, Wei Cui ${ }^{2}$, Bingweng Liu $^{3}$
}

\begin{abstract}
Background: It is well known that certain non-thyroidal critical illness may lead to euthyroid sick syndrome(ESS). There are little reports about the change of thyroid hormone in the children's central nervous system (CNS) infections.

Results: The results of serum $\Pi 3, \Pi 4$ and TSH in these children were compared with those in 20 cases of healthy adults and 20 cases of adults with primary hypothyroidism. Serum T3 and T4 were decreased in 34/78 children with CNS infections, T3 and T4 were much lower than those of healthy adult $(p<0.05)$, but still higher than that of the primary hypothyroidism ( $p<0.05$ ), and TSH levels were not significant differences among children with CNS infections and children with non-CNS infections ( $p>0.05$ ).

Low T3 and T4 levels in serum and cerebrospinal fluid(CSF)were predominant in children with serious infections of CNS, 31/34 (percent 91.17) cases of serious CNS infection had low serum TT3 and/or TT4. The low T3 with low T4 was seen in 14/34 children of severe CNS infections, 3 of them died. The levels of CSF T3 (X \pm SD $=0.39 \pm 0.47$ $\mathrm{ng} / \mathrm{ml})$ and $\mathrm{T} 4(\mathrm{x} \pm \mathrm{SD}=1.02 \pm 1.27 \mathrm{ug} / \mathrm{dl})$ in the serious CNS infections were lower than that of non-CNS infections T3 $(x \pm S D=0.93 \pm 1.23 \mathrm{ng} / \mathrm{ml})$, and T4 $(x \pm S D=2.42 \pm 1.70 \mathrm{ug} / \mathrm{dl})$, 7 died children were all in the subjects of low T3 and/or low T4.

In 22 children with non-CNS infections, serum T3 and T4 levels were lower than that of healthy adult, but have not significant difference $(p>0.05)$.

Conclusions: These results suggest that detection of $\Pi 3, \pi 4$ and TSH in serum and/or CSF simultaneous or alone in analyses would be valuable in correctly judging thyroid function and evaluating the prognosis of the children with infections of CNS. Measuring a little amount of blood (1 ml)or CSF required for this method is a simple, convenient and accurate method.
\end{abstract}

\section{Background}

Numerous studies have demonstrated a high incidence of hypothyroidism in non-thyroidal illness in general. Anyone who has worked in an intensive care unit is aware of the phenomenon commonly referred to as the nonthyroidal illness syndrome (NTIS) or euthyroid sick syndrome (ESS), observed in approximately $44 \%$ of these patients [1]. Abnormalities in thyroid function tests in patients with non-thyroidal illness may be divided into low T3 syndrome, low T3 and low T4 syndrome, high T4 syndrome and a mixed form. Hence it is becoming

\footnotetext{
* Correspondence: jiaofy@yeah.net

'Department of Pediatrics, Shaanxi Provincial People's Hospital, Xi, an, China Full list of author information is available at the end of the article
}

clear that the conversion of T4 to T3 can vary according to the clinical state, which can therefore influence the metabolic action of thyroid hormone and the function of hypothalamo-pituitary-thyroid axis.

The severity of these neuroendocrine alterations was shown to be related to adverse outcome of patients in the intensive care unit [2]. When thyroxine (T4) falls to $<4 \mu \mathrm{g} / \mathrm{dl}$, the risk of death rises to $\sim 50 \%$, and when $\mathrm{T} 4$ falls to $<2 \mu \mathrm{g} / \mathrm{dl}$, mortality increases even more to $\sim 80 \%[3,4]$.

There are little reports about the change of thyroid hormone in the central nervous system (CNS) infections of children. We have measured total T3 and T4 concentration of serum and/or cerebrospinal fluid (CSF) in 
children with infections of CNS, in healthy adults and in adults with primary hypothyroidism, children with nonCNS infections respectively, in order to find the changes of thyroid hormone in serum and/or CSF in relation to CNS infections.

\section{Methods}

The study included 145 children of non-thyroidal illnesses, 93 male and 52 female. 123 with CNS infections and 22 with non-CNS infections. Out of the 123 with CNS infections, 39 had purulent meningitis, 7 meningococcal meningitis, 21 tuberculous meningitis and 56 viral encephalitis. The classify of severity of CNS infections was based on the clinical manifestation and laboratory examinations, and electroencephalogram (EEG) examination. The severe CNS infections had these symptoms such as seizure, respiratory failure, conscious disturbance, persistent fever, and obviously abnormality in EEG. Out of 22 children with non-CNS infections, 16 had urinary system diseases, 6 had respiratory system diseases. In addition, we have measured 20 adults of primary hypothyroidism; 20 cases of healthy adult. The Patient characteristics appear in table 1. Samples of serum and CSF were collected from children with nonthyroidal illness in our hospital. The diagnosis was based on the clinical manifestation and laboratory examinations of blood and CSF, and EEG examination. No children had thyroid malformation and history of thyroid diseases.

Serum and/or cerebrospinal fluid (CSF) concentration of total triiodothyronine (TT3) and total thyroxine (TT4) and thyrotropin (TSH) were measured in 145 children of non-thyroidal illness, in which 123 children were CNS infections. We measured serum and CSF T3 and T4 in 36/123 children, serum T3 and T4 in 42/123 children, CSF T3 and T4 in 45/123 children. We also measured CSF T3 and T4 in 6 children with respiratory system diseases. The results of serum T3, T4 and TSH in the children with non-thyroidal illness were compared with those in 20 cases of healthy adults and 20 cases of adults with primary hypothyroidism.

\section{Table 1 subjects characteristics}

\begin{tabular}{lcll}
\hline Groups & Number & Age (years) & Sex (male/female) \\
\hline Purulent meningits & 39 & $6 \pm 6.97$ & $24 / 15$ \\
Meningococal meningits & 7 & $7 \pm 6$ & $4 / 3$ \\
Tuberculous meningits & 21 & $7.2 \pm 6.1$ & $15 / 6$ \\
Viral encephlitis & 56 & $6.8 \pm 6.2$ & $34 / 22$ \\
Respiratory system disease & 6 & $7.5 \pm 5.6$ & $4 / 2$ \\
Hypothoridism & 20 & $30 \pm 12$ & $12 / 8$ \\
Healthy adult & 20 & $32 \pm 13$ & $12 / 8$ \\
Urinary system disease & 16 & $8 \pm 6$ & $10 / 6$
\end{tabular}

The serum and CSF samples were obtained by venipuncture and lumbar puncture before initial treatment. The specimens were stored at $-20^{\circ} \mathrm{C}$ until analysis. The serum and CSF T3, T4 and TSH were measured by radioimmunoassay (RlA), the serum and CSF T3 and T4 were measured by double-antibody plus PEG, and the serum TSH was measured by double-antibody. Radioimmunoassay kit is manufactured by institute technique of analysis in Shanghai and Sichuan, China.

All samples were measured with double-tubules, then re-measured by Type FJ-2000 $\mathrm{R}$ counter radioimmunoassay (made in Xian National 262 factory). The rate of recovery in T3 and T4 were 96 to 108 percent, coefficient of variation $(\mathrm{CV})$ within the batch and $\mathrm{CV}$ among the batch in T3 and T4 were 6 to 7 percent and 8 to 9 percent respectively. The rate of recovery of TSH was 97.8 percent, $\mathrm{CV}$ within the batch and $\mathrm{CV}$ among the batch were 6 percent and 4.8 percent respectively. Each measurement was required to be $<0.04$ for reaction error relation (RER). Data were expressed as mean \pm standard deviation $(\mathrm{X} \pm \mathrm{SD})$. Student's T-test was used for statistical comparisons. T'-test was used when variance not rule. P Value of 0.05 or less was considered statistically significant. The normal values of TT3,TT4, $\mathrm{TSH}$ are $1.21 \pm 0.43 \mathrm{ng} / \mathrm{ml}, 9.06 \pm 3.15 \mathrm{u} \mathrm{g} / \mathrm{dl}, 3.53 \pm$ $0.42 \mathrm{mu} / \mathrm{l}$ respectively.

\section{Results}

The level of serum TT3, TT4 and TSH in all subjects appear in table 2. Serum T3 and T4 were decreased in $34 / 78$ children with severe CNS infections, T3 and T4 were much lower than those of healthy adult $(\mathrm{p}<0.05)$, and TSH levels were not significant differences among children with CNS infections and children with nonCNS infections $(p>0.05)$. In 22 children with non-CNS infections, serum T3 and T4 levels were lower than that of healthy adult, but have not significant difference ( $\mathrm{p}>$ 0.05). 37/78 children with CNS infections had low T3 and/or low T4 in the serum. Among them, 31/37 children were severe infections. 14/31 children with low T4 accompanied by low T3, all them were severe patients, 3 of them died.

The CSF T3 and T4 level in 87 children of CNS infections and 6 children of respiratory system diseases appear in table 3.60/87 children were mild, other (27/ 87) were severe. The mild were low T3 and low T4 in CSF, than that of non-CNS infections, but had not statistically significant $(\mathrm{p}>0.05)$. The CSF T4 in severe children was much lower than that of non-CNS infections $(\mathrm{p}<0.05)$.

\section{Discussion}

This study presents evidence of thyroid dysfunction, expressed as a lower TT3 and TT4 in serum and CSF in 
Table 2 The level of serum $T_{3}, T_{4}$ and TSH in all subjects

\begin{tabular}{|c|c|c|c|c|}
\hline Groups & Number & $\Pi_{3}(\mathrm{ng} / \mathrm{ml}) \mathrm{t} / \mathrm{p} X \pm S D$ & $\pi_{4}(\mathrm{ug} / \mathrm{dl}) \mathrm{t} / \mathrm{p} X \pm S D$ & $T S H(m u / l) t / p X \pm S D$ \\
\hline CNS infection mild & 44 & $1.01 \pm 0.37 \mathrm{NS} ※$ & $8.90 \pm 2.67$ NS※ & $4.20 \pm 2.04$ NS※ \\
\hline CNS infection severe & 34 & $0.58 \pm 0.28<0.05 ※$ & $5.14 \pm 3.42<0.05 ※$ & $4.79 \pm 2.04<0.05 ※$ \\
\hline Hypothoridism & 20 & $0.29 \pm 0.13<0.01 ※$ & $2.93 \pm 1.51<0.01 ※$ & $9.06 \pm 2.76<0.01 ※$ \\
\hline Healthy adult & 20 & $1.05 \pm 0.36$ & $8.16 \pm 1.30$ & $4.74 \pm 0.99$ \\
\hline $\begin{array}{l}\text { Urinary system } \\
\text { disease }\end{array}$ & 16 & $0.87 \pm 0.49$ NS $※$ & $7.88 \pm 3.34$ NS※ & $5.40 \pm 2.05 \mathrm{NS} \circledast$ \\
\hline $\begin{array}{l}\text { Respiratory system } \\
\text { disease }\end{array}$ & 6 & $0.63 \pm 1.12 \mathrm{NS} ※$ & $6.53 \pm 1.07$ NS $※$ & $4.97 \pm 1.83$ NS $※$ \\
\hline
\end{tabular}

※compared with healthy adult.

children with CNS infections. These findings are in keeping with those of other investigators. Three further findings were observed in the 123 children with CNS infections: (1) the mean T3 and T4 in serum and the mean T4 in CSF were significantly lower in children with severe CNS infections than that in healthy adults $(\mathrm{P}<0.05)$; (2) The decrease of CSF T4 was higher than that of T3 in children with severe CNS infections; (3) the children with low $\mathrm{T} 3$ showed lower survival rate than those with low T4. The data have showed that T3 and $\mathrm{T} 4$ in serum are more decreased in severe infections of CNS than that in the mild.

Our data showed that the total T3 and T4 in CSF were much lower than serum T3 and T4 in children with severe CNS infection. This phenomenon can be explained by the fact that brain capillaries have tight junctions, and in this respect it is unlike microvessels of other organ, the brain may be tentatively regarded as a representative peripheral tissue because plasma albumin, thyroid-hormone-binding prealbumin or binding globulins do not cross the brain capillary bed. Thyroid hormones have a low intrinsic permeability in brain endothelia and only small amounts of hormone cross the brain capillary wall via free diffusion. The levels of CSF T3 and T4 in children with severe CNS infections were lower than those in children with nonCNS infections. Thyroid hormone transport system and endothelial permeability in brain could be impaired when suffer from severe CNS infections, so that T3 and T4 in CSF are much decreased. The results show dynamic variation of total serum and CSF T4 and T3 concentrations in accordance with degree of children's conditions.

Table 3 The level of CSF $T_{3}$ and $T_{4}$ in patients with CNS infections

\begin{tabular}{lcll}
\hline Groups & Number & $\begin{array}{l}T_{3}(\mathrm{ng} / \mathrm{ml}) \mathrm{t} / \mathrm{p} X \\
\pm S D\end{array}$ & $\begin{array}{l}T_{\mathbf{4}}(\mathrm{ug} / \mathrm{dl}) \mathrm{t} / \mathrm{p} X \\
\pm \mathrm{SD}\end{array}$ \\
\hline $\begin{array}{l}\text { Respiratory system } \\
\text { disease }\end{array}$ & 6 & $0.93 \pm 1.23$ & $2.42 \pm 1.70$ \\
CNS infection mild & 60 & $0.56 \pm 0.40 \mathrm{NS} ※$ & $3.81 \pm 2.88 \mathrm{NS} ※$ \\
CNS infection severe & 27 & $0.39 \pm 0.47 \mathrm{NS} ※$ & $\begin{array}{l}1.02 \pm 1.27 \\
\end{array}$ \\
\end{tabular}

※compared with non-CNS infections.
The mean T3 and T4 of serum by RIA in children with severe CNS infections was lower than that in the healthy adults. The cause of the low T3 level is that production decreases rather than degradation or clearance increase. In this situation, the organism can rapidly reduce its metabolic rate, while serum $\mathrm{T} 3$ decreases and reverse $\mathrm{T} 3$ increases, so that gain to energy balance. The decreased formation of $\mathrm{T} 3$ is reported to be accompanied by an increased reversed T3 (r-T3) value, caused by a reduction of its metabolic clearance as a result of impaired 5'-deiodinase enzyme activity. With the progression of the severity of CNS infections, there is a tendency for total T4 levels to fall. Although many studies have endeavored to evaluate the test to show that the patient with nonthyroidal illness is euthyroid, the serum thyroid hormone levels are subnormal in some patients with a severe systemic illness.

The most common pattern is a decrease in total and unbound triiodothyronin (T3) with normal levels of thyroid stimulating hormone (TSH) and thyroxin (T4). This is classified as SES type 1 (SES-1) or low-T3 syndrome. Classic SES-1 was found in several studies in children, including after bone marrow transplant [5], in Hodgkin's disease, hepatitis, metabolic acidosis due to diarrhoea or diabetic ketoacidosis and sepsis [6]. The de-ionidation from T4 to T3 via peripheral (hepatic) enzymes (inhibition of 5'-deionidase, a selenoenzyme) which is impaired, leading to a decrease of $\mathrm{T} 3$ [7]. In general, the severity of illness is correlated to the severity of SES [8]. Very sick patients may show a dramatic fall in total T3 and T4 levels; this state is called the low-T4 syndrome or SES type 2 (SES-2) and has a poor prognosis [9]. Patients with low or undetectable TSH show increased morbidity and mortality $[10,11]$. Additionally, the response of TSH to thyroid releasing hormone (TRH) is impaired in SES. It was confirmed by Chinga-Alayo and colleagues that the degree of SES seems to have significant influence on a patient's outcome under various conditions [12]. SES-1 is related to good outcome and mild to moderate illness, SES-2 is related to severe illness and poor outcome. 


\section{Conclusions}

Measuring TT3, TT4 and TSH in a little amount of blood $(1 \mathrm{ml})$ or CSF from the children with infections of CNS is simple, convenient and accurate. Our studies have showed that detection of T3, T4 and TSH in serum and/or in CSF would be valuable in correctly judging thyroid function and evaluating the prognosis of the children with infections of CNS.

\section{Acknowledgements}

The authors as well would like to thank Dr Xiaoli Hui who improved the quality of the written English by her assistance with language fluency and grammar checking for of this paper.

\section{Author details}

'Department of Pediatrics, Shaanxi Provincial People's Hospital, Xi, an, China. ${ }^{2}$ Department of Pediatrics, The Second Teaching Hospital, Yanan Medical College, Suide, China. ${ }^{3}$ Department of nuclear medicine, The Second Teaching Hospital, Yanan Medical College, Suide, China.

\section{Authors' contributions}

FYJ initiated the idea of the study, participated in its design, performed the statistical analysis of the results, participated in the coordination and drafted the manuscript. He is the corresponding author of the paper. XYZ performed the statistical analysis of the results, participated in the coordination and helped to draft the manuscript. TMB participated in the sequence alignment and helped to draft the manuscript. All authors have read and approved the final version of the manuscript.

\section{Competing interests}

The authors declare that they have no competing interests.

Received: 19 October 2010 Accepted: 11 February 2011

Published: 11 February 2011

\section{References}

1. Plikat K, Langgartner J, Buettner R, et al: Frequency and outcome of patients with nonthyroidal illness syndrome in a medical intensive care unit. Metabolism 2007, 56:239-244.

2. Peeters RP, Wouters PJ, van Toor H, Kaptein E, Visser TJ, Van den Berghe G: Serum 3,3',5'-triiodothyronine (rT3) and 3,5,3'-triiodothyronine/rT3 are prognostic markers in critically ill patients and are associated with postmortem tissue deiodinase activities. J Clin Endocrinol Metab 2005, 90:4559-4565.

3. De Groot LJ: Non-thyroidal illness syndrome is a manifestation of hypothalamic-pituitary dysfunction, and in view of current evidence, should be treated with appropriate replacement therapies. Crit Care Clin 2006, 22:57-86.

4. Adler SM, Wartofsky L: The nonthyroidal illness syndrome. Endocrinol Metab Clin North Am 2007, 36:657-672.

5. Matsumoto $M$, Ishiguro $H$, Tomita $Y$, Inoue $H$, Yasuda $Y$, Shimizu $T$, Shinagawa T, Hattori K, Yabe H, Kubota C, et al: Changes in thyroid function after bone marrow transplant in young patients. Pediatr Int 2004, 46:291-295.

6. Yildizdas D, Onenli-Mungan N, Yapicioglu H, Topaloglu AK, Sert-demir Y, Yuksel B: Thyroid hormone levels and their relationship to survival in children with bacterial sepsis and septic shock. J Pediatr Endocrinol Metab 2004, 17:1435-1442.

7. Kelly GS: Peripheral metabolism of thyroid hormones: a review. Altern Med Rev 2000, 5:306-333.

8. Ray DC, Macduff A, Drummond GB, Wilkinson E, Adams B, Beckett GJ: Endocrine measurements in survivors and non-survivors from critical illness. Intensive Care Med 2002, 28:1301-1308.

9. Peeters RP, Wouters PJ, van Toor H, Kaptein E, Visser TJ, Vanden Berghe G: Serum 3,3',5'-triiodothyronine ( $\mathrm{rT} 3$ ) and 3,5,3'-triiodothyronine/rT3 are prognostic markers in critically ill patients and are associated with postmortem tissue deiodi-nase activities. J Clin Endocrinol Metab 2005, 90:4559-4565.

10. Zargar AH, Ganie MA, Masoodi SR, Laway BA, Bashir MI, Wani Al, Salahuddin M: Prevalence and pattern of sick euthyroid syndrome in acute and chronic non-thyroidal illness: its relationship with severity and outcome of the disorder. J Assoc Physicians India 2004, 52:27-31.

11. Miguel Bayarri V, Borras Palle S, Murcia Llacer B, Sancho Chinesta S, Malaga Lopez A, Sola Izquierdo E, Perez Bermudez B, Hernandez Mijares A: Prevalence and prognosis significance of euthyroid sick syndrome in critical illness. Rev Clin Esp 2001, 201:572-574.

12. Chinga-Alayo E, Villena J, Evans AT, Zimic M: Thyroid hormone levels improve the prediction of mortality among patients admitted to the intensive care unit. Intensive Care Med 2005, 31:1356-1361.

doi:10.1186/1824-7288-37-11

Cite this article as: Jiao et al:: Clinical evaluation of the function of hypothalamo-pituitary-thyroid axis in children with central nervous system infections. Italian Journal of Pediatrics 2011 37:11.

\section{Submit your next manuscript to BioMed Central and take full advantage of:}

- Convenient online submission

- Thorough peer review

- No space constraints or color figure charges

- Immediate publication on acceptance

- Inclusion in PubMed, CAS, Scopus and Google Scholar

- Research which is freely available for redistribution 